\title{
CÓPULA INVARIÁVEL EM CLIVADAS INVERTIDAS: UM EXEMPLO DE GRAMATICALIZAÇÃO?
}

\author{
Invariable copula in inverted cleft sentences: \\ An example of grammaticalization?
}

\begin{abstract}
Damaris Matias Silveira Doutoranda do Programa de Pós-Graduação em Linguística da Universidade Federal de Santa Catarina damysilveira@gmail.com
\end{abstract}

Resumo: Esta pesquisa busca investigar diacronicamente as sentenças sintaticamente utilizadas para focalizar constituintes, as clivadas canônicas e invertidas. Tais sentenças caracterizam-se pelas sequências Cópula + Foco + que + IP e Foco + cópula + que + IP. O período considerado para a busca dessas sentenças é o que se estende do século XVI ao XIX, textos que compõem o Corpus Histórico do Português Tycho Brahe. Tento apresentar uma discussão em torno da gramaticalização da cópula das clivadas invertidas através da maior evidência para o fenômeno: a ausência de concordância temporal entre a cópula e o verbo da sentença encaixada.

Palavras-chave: Construções clivadas; Gramaticalização; Concordância.

\begin{abstract}
The present research aims to investigate diachronically sentences used to syntactically focalize constituents, the canonical and inverted clefts one. Such sentences are characterized by the sequences copula + Focus + que + IP and Focus + copula + que $+I P$. The research period range from the $16^{\text {th }}$ to the $19^{\text {th }}$ century, utilizing texts that make up the Tycho Brahe Parsed Corpus of Historical Portuguese. I try to present a discussion on the grammaticalization of the copula in inverted clefts trough the most important evidence from the phenomenon: the absence of tense agreement between the copula and the verb of the subordinate clause.
\end{abstract}

Keywords: Cleft constructions; Grammaticalization; Agreement. 


\section{Introdução}

O recurso da clivagem no português apresenta um campo fecundo para a pesquisa, em especial no âmbito da diacronia, visto que são poucos os estudos em torno do comportamento sintático dessas sentenças ao longo do tempo. Dispomos, entretanto, de análises significativas a respeito da evolução dessas sentenças, como Kato e Ribeiro (2006) e Kato (2009), sendo que, neste último, Kato trata com especial atenção da gramaticalização envolvendo sentenças clivadas

Sentenças clivadas invertidas apresentam relação de concordância temporal mais limitada entre a cópula e o verbo da sentença encaixada, quando este não se encontra no tempo presente, em comparação com as clivadas canônicas. Nesse caso, é bastante produtivo, em português brasileiro, sentenças clivadas invertidas sem a concordância mencionada acima, o que é defendido por Kato como resultado de gramaticalização:

(1) A Maria é que comeu o bolo.

Para melhor observar o comportamento da cópula em clivadas invertidas, foi feita, no presente estudo, uma busca em 16 textos anotados do corpus histórico do Português - Tycho Brahe. Desses textos foram retiradas as clivadas invertidas encontradas, bem como as clivadas canônicas. Todas as referências temporais aos dados correspondem ao nascimento do autor e não à data em que foram escritos.

O estudo aqui a presentado se trata da descrição dos dados encontrados no corpus Tycho Brahe, sendo que, o que pretendo é observar as ocorrências e levantar possíveis discussões que possam contribuir para estudos futuros, a fim de reforçar a idéia de gramaticalização da cópula nas sentenças clivadas invertidas ao longo do tempo.

\section{Clivadas canônicas e invertidas}

A clivagem é um recurso sintático utilizado pelo falante a fim de focalizar constituintes. Através desse processo são formadas sentenças clivadas, que apresentam a sequência Cópula + XP (foco) + que + IP na sua forma canônica: 
(2)É a Maria que estuda linguística.

Apesar da existência de um padrão canônico para as clivadas, o foco da sentença pode aparecer anterior à cópula, resultando no que chamamos de clivadas invertidas, que apresentam a sequência Foco+cópula+que:

(3) A Jurema é que estuda linguística.

Através da clivagem, temos também as sentenças pseudo-clivadas, que se diferenciam das clivadas por apresentarem um elemento Wh no CP onde as clivadas alojam um complementizador. As sentenças estudadas nessa pesquisa, entretanto, serão as do padrão apresentado em (3), ou seja, as clivadas invertidas que trazem a sequência Foco + cópula + que, bem como as canônicas, como (2), para fins de comparação. Esses dois tipos de sentença serão úteis no levantamento de hipóteses, que podem contribuir em defesa da hipótese de gramaticalização.

\section{Gramaticalização}

Este estudo discute a idéia de gramaticalização da cópula em clivadas invertidas ao longo do tempo, ou seja, o modo como o verbo ser vai adquirindo ao longo do tempo, de maneira gradual, o caráter de elemento focalizador. Hopper e Traugott (1993) apontam para dois significados o termo gramaticalização. Um deles está relacionado com fenômeno da linguagem em si, e se refere aos estágios em que itens se tornam mais gramaticais ao longo do tempo. O outro sentido para o termo está ligado ao quadro de pesquisa e se refere à parte do estudo da mudança linguística que se concentra em questões como: de que forma itens lexicais vêm ao longo do tempo a desenvolver funções gramaticais?

O termo "gramaticalização" foi introduzido por Meillet (1912), onde o autor assume que as transformações gramaticais envolvem dois processos, um deles é a analogia, que é a composição de uma forma a partir do modelo de uma outra, como por exemplo a conjugação de um verbo a partir do modelo de um outro: bebeu/fazeu. Outro processo envolvido na gramaticalização é a atribuição de caráter gramatical a uma palavra que já 
foi autônoma, que é o que pode supostamente ter ocorrido com a cópula das clivadas invertidas.

Hopper e Traugott (1993) chamam de reanálise o processo pelo qual as propriedades gramaticais e semânticas são modificadas, ou seja, as modificações comprometem o sentido do elemento. Segundo os autores, a reanálise é o processo mais importante tanto para a gramaticalização, quanto para os outros tipos de mudança, pois ela constitui um pré-requisito para o desenvolvimento da mudança através da analogia.

Lightfoot (2006) aponta para a relação entre semântica e a noção introduzida por Meillet, no sentido de que a gramaticalização está relacionada com a tendência de um item de sentido pleno, perder a carga significativa ao longo do tempo, passando a ser usado com funções gramaticais. Essa noção será muito importante para essa pesquisa, ou seja, a semântica do item estudado é imprescindível na tentativa de explicar a possibilidade de gramaticalização da cópula.

Mais precisamente, tentarei observar o que postula Meillet (1912): como um item perde a sua expressividade linguística autônoma e seu valor semântico, passando a elemento auxiliar e se tornando mais acessório -no caso do fenômeno aqui estudado, a ponto de poder ser apagado.

Este estudo compreende a necessidade de considerar tanto a sintaxe quanto a semântica na tentativa de discutir a gramaticalização da cópula. Gelderen (2004) mostra que a relação entra a gramaticalização e a gramática gerativa é um pouco conturbada. Os teóricos da teoria gerativa acreditam que a sintaxe é autônoma, enquanto os teóricos da gramaticalização veem tanto a função quanto o significado como fatores determinantes por trás da mudança linguística. Nesta pesquisa, é possível observar que há evidências sintáticas para a gramaticalização, que seria a ausência de concordância, mas, no âmbito da semântica, também encontramos respostas no que tange a perda de carga significativa do verbo. Além disso, a reanálise proposta aqui envolve uma importante mudança no significado do elemento. Isso será melhor explicado mais adiante.

Nessa perspectiva, irei assumir aqui que a gramaticalização envolve o processo pelo qual um item lexical adquire e efetua funções gramaticais ao longo do tempo. No caso desta pesquisa, esse item se trata da cópula nas sentenças clivadas invertidas e serão considerados para esta análise fatores sintáticos e semânticos envolvidos na gramaticalização desse elemento, seja por meio de evidências ou motivações para essa mudança. 
Para a melhor compreensão do que vem a ser um termo lexical e um termo gramatical, retomo Hopper e Traugott (1993) que mostram a distinção comumente aceita entre palavras de conteúdo e palavras funcionais. As primeiras servem para se relacionar ou descrever coisas, ações e qualidades. Exemplos de palavras de conteúdo são nomes, verbos e adjetivos, que serão aqui tratados como 'itens lexicais'. Já as palavras funcionais, doravante 'itens funcionais', servem para estabelecer relações entre termos nominais, ligar partes do discurso, indicar quais elementos do discurso já estão identificados ou não e para mostrar qual a proximidade que esses itens estão do falante. São exemplos, entre outros, de itens funcionais: conectivos, pronomes e demonstrativos.

No caso das clivadas invertidas, portanto, pretendo verificar a possibilidade de a cópula passar a ser um item mais funcional. Vale lembrar que o verbo ser não possui a mesma riqueza semântica que um verbo como comer, por exemplo, ainda mais se assumirmos que a cópula não atribui papel temático do mesmo modo que outros verbos. Em uma sentença como "A Maria é bonita", não é a cópula que atribui papel temático a $A$ Maria, mas sim o adjetivo bonita, enquanto que um verbo como comer atribui papel temático a um agente e um tema. A cópula já traz em si funcionalidade, mas no caso das clivadas invertidas, ela se torna ainda mais gramatical.

Portanto, a priori, a cópula já não é a melhor manifestação da lexicalidade de um verbo. Mesmo assim, ela ainda carrega traços de concordância temporal e pessoal como os demais verbos. Se nas clivadas a cópula realmente está em um processo de perda de concordância, ela se aproxima da invariabilidade e perde um traço importante do estatuto verbal, o que nos faz suspeitar, à esteira de Kato, que a cópula não tem a função de verbo, mas está gramaticalizada, desempenhando unicamente o papel de focalizador.

\section{Invariabilidade da cópula = gramaticalização?}

\subsection{Dados}

Conforme já mencionado, para melhor apreciação do fenômeno em questão, foi feita uma busca em 16 textos do corpus Tycho Brahe, cujos autores são nascidos entre os séculos XVI e XIX. O banco de dados disponibiliza de um total de 73 textos para pesquisa livre, sendo que 19 possuem anotação sintática, o que faculta buscas por sentenças com características específicas, onde se enquadram os textos usados neste estudo: 
Tabela 1. Relação de textos do corpus Tycho Brache utilizados neste estudo

\begin{tabular}{lll} 
AUTOR & Ref. & Título \\
\hline Século 16 & & \\
$(1502-1579)$ PERO MAGALHÃES DE GANDAVO & g_008 & História da Província de Santa Cruz \\
$(1510-1583)$ FERNAO MENDES PINTO & p_001 & Perigrinação \\
$(1542-1606)$ DIOGO DO COUTO & c_007 & Décadas \\
(1556-1632) LUIS DE SOUSA & s_001 & A Vida de Frei Bartolomeu dos Mártires \\
\hline Século 17 & & \\
(1597-1665) MANUEL DE GALHEGOS & g_001 & Gazeta \\
(1608-1697) ANTONIO VIEIRA & v_004 & Sermões \\
(1658-1753) MARIA DO CEU & c_002 & Vida e Morte de Madre Helena da Cruz \\
(1675-1754) ANDRE DE BARROS & b_001 & Vida do apostólico padre Antonio Vieira \\
\hline Século 18 & & \\
(1702-1783) CAVALEIRO DE OLIVEIRA & c_001 & Cartas, Cavaleiro de Oliveira \\
(1705-1763) MATIAS AIRES & a_001 & Reflexões sobre a Vaidade dos Homens \\
(1750-1839) MARQUESA D'ALORNA & a_004 & Cartas, Marquesa de Alorna \\
(1757-1832) JOSE DANIEL RODRIGUES DA COSTA & c_005 & Entremezes de Cordel \\
\hline Século 19 & & Theatro: Falar verdade a mentir; \\
(1799 - 1854) J.B. DA SILVA L. DE ALMEIDA GARRETT & g_004 & As Prophecias do Bandarra e Camões do Rocio \\
(1802-1881) MARQUES DE F.E ALORNA & a_003 & Memórias do Marquês da Fronteira e Alorna \\
(1825-1890) CAMILO CASTELO BRANCO & b_005 & Maria Moisés \\
(1836-1915) RAMALHO ORTIGAO & o_001 & Cartas a Emília, Ramalho Ortigão \\
\hline & & \\
\hline
\end{tabular}

Destes textos foram extraídos dados de clivadas canônicas e invertidas, sendo que as relações de (não) concordância entre elas variaram entre:

- clivadas invertidas com concordância temporal de passado entre a cópula e o verbo da sentença encaixada:

(4) História foi que não ficou em segredo e chegou às orelhas da Raínha que, como tão grande católica, a estimou e nela renovou o gosto da boa eleição que fizera do prelado. (Pero Magalhães de Gandavo (n. 1502)) 
- clivadas invertidas com concordância temporal de presente entre a cópula e o verbo da sentença encaixada:

(5) Assim é que se criam os fortes. (Ramalho Ortigão (n.1836))

- clivadas invertidas sem concordância temporal entre a cópula e o verbo da encaixada:

(6) Ali é que ela dormia. (Camilo castelo Branco (n.1826))

Abaixo, especifico o número de ocorrências das clivadas invertidas com e sem concordância encontradas nos textos:

Tabela 2. Ocorrências de clivadas invertidas e sem concordância encontradas no corpus $^{1}$

\begin{tabular}{|c|r|r|r|}
\hline Texto (ano) & Concordância & $\begin{array}{c}\text { Ausência de } \\
\text { concordância }\end{array}$ & Total \\
\hline 1556 & 1 & - & 1 \\
\hline 1608 & 3 & 1 & 4 \\
\hline 1702 & 6 & - & 6 \\
\hline 1705 & 19 & - & 19 \\
\hline 1750 & 20 & 9 & 29 \\
\hline 1757 & 3 & 3 & 6 \\
\hline 1802 & 1 & 10 & 11 \\
\hline 1826 & 5 & 3 & 8 \\
\hline 1836 & 8 & 3 & 11 \\
\hline
\end{tabular}

As clivadas invertidas com concordância temporal de passado desencadeiam papel importante nesta análise, pois são os exemplos encontrados no corpus onde melhor se pode observar a distância da gramaticalização, já que a cópula concorda com o verbo da sentença encaixada, e, portanto, carrega uma importante característica do estatuto de verbo, não sendo, portanto, invariável. Exemplos desse tipo foram muito raramente encontrados: apenas uma ocorrência no texto Luis de Sousa (n. 1556) e outra no de Ramalho Ortigão (n. 1836).

\footnotetext{
${ }^{1}$ Nos gráficos e tabelas de ocorrências de clivadas canônicas e invertidas deste estudo constam apenas os dados de textos que possuíam esses tipos de sentença.
} 
Já os exemplos de invertidas com concordância de presente seriam casos ambíguos, pois a cópula pode estar concordando com o verbo, ou apresentando a forma invariável, sendo que a concordância seria coincidência, pelo fato do evento indicado pela encaixada estar no presente do mesmo modo que a invariabilidade da cópula tem a forma de presente. Considerando essa abrangência, esse foi o modelo mais encontrado ao longo dos séculos.

Quanto aos casos sem concordância, que são as ocorrências mais visíveis do que é defendido como gramaticalização, nos dados encontrados no corpus Tycho Brahe, as evidências não são tão significativas até metade do século XVIII. A partir dai é que os exemplos de invariabilidade da cópula começam a evoluir.

Para tentar explicar melhor o fenômeno e levantar possíveis hipóteses, foi feito o mesmo levantamento com relação às clivadas canônicas, verificando se, nos textos do corpus, a concordância nessas sentenças se verifica. $\mathrm{O}$ resultado foi o seguinte:

Tabela 3. Ocorrências de clivadas canônicas com e sem concordância encontradas no corpus

\begin{tabular}{|c|r|l|r|}
\hline Texto (ano) & Concordância & $\begin{array}{c}\text { Ausência de } \\
\text { concordância }\end{array}$ & Total \\
\hline 1502 & 1 & - & 1 \\
\hline 1556 & 2 & - & 2 \\
\hline 1702 & 10 & 1 & 11 \\
\hline 1705 & 2 & - & 2 \\
\hline 1750 & 5 & - & 5 \\
\hline 1757 & 1 & - & 1 \\
\hline 1802 & 33 & 2 & 35 \\
\hline 1826 & 9 & - & 9 \\
\hline 1836 & 19 & - & 19 \\
\hline
\end{tabular}

Como mostra a tabela, o comportamento das canônicas não foi o mesmo das invertidas nos textos do corpus. Nas clivadas canônicas, o uso de concordância é quase que total a não ser por três exemplos encontrados. Nesses exemplos a cópula estava no presente e o verbo da encaixada no futuro ou no passado. A comparação com as clivadas canônicas será importante no levantamento da discussão mais adiante. 


\subsection{Discutindo o fenômeno}

Considerando a necessidade de mais dados para poder tirar conclusões mais sólidas a respeito do fenômeno da gramaticalização, é tarefa arriscada fazer muitas afirmações sobre o comportamento da cópula em clivadas invertidas o longo do tempo com base no corpus, em especial, se considerarmos a ambiguidade nas sentenças clivadas invertidas com concordância de presente, pois não sabemos se se trata de um verbo que concorda com a sentença encaixada, ou de uma cópula invariável, que também ocorre com a forma no presente do verbo ser.

O que pode mostrar a gramaticalização de forma mais explícita são os exemplos sem concordância, com cópula no presente e sentença encaixada no passado ou no futuro. Seguramente, pode-se dizer: é claramente evidente o aumento das ocorrências de clivadas invertidas a partir da segunda metade do século XVIII ${ }^{2}$ e juntamente com isso o aumento de ocorrências sem concordância, ou seja, a inversão de clivadas e a invariabilidade da cópula são proporcionais. Podemos dizer que ausência de concordância temporal é uma característica, não exclusiva, mas que aparece mais tipicamente em clivadas invertidas. Os gráficos abaixo auxiliam a visualizar melhor a relação entre o tempo e as ocorrências entre as clivadas canônicas e invertidas:

\footnotetext{
${ }^{2}$ A evolução dessas sentenças a partir do século XVIII, em textos do corpus Tycho Brahe, fica mais evidente nos dados da análise diacrônica em torno das clivadas de Silveira (2014).
} 
Gráfico 1. Concordância de clivadas canônicas ao longo do tempo

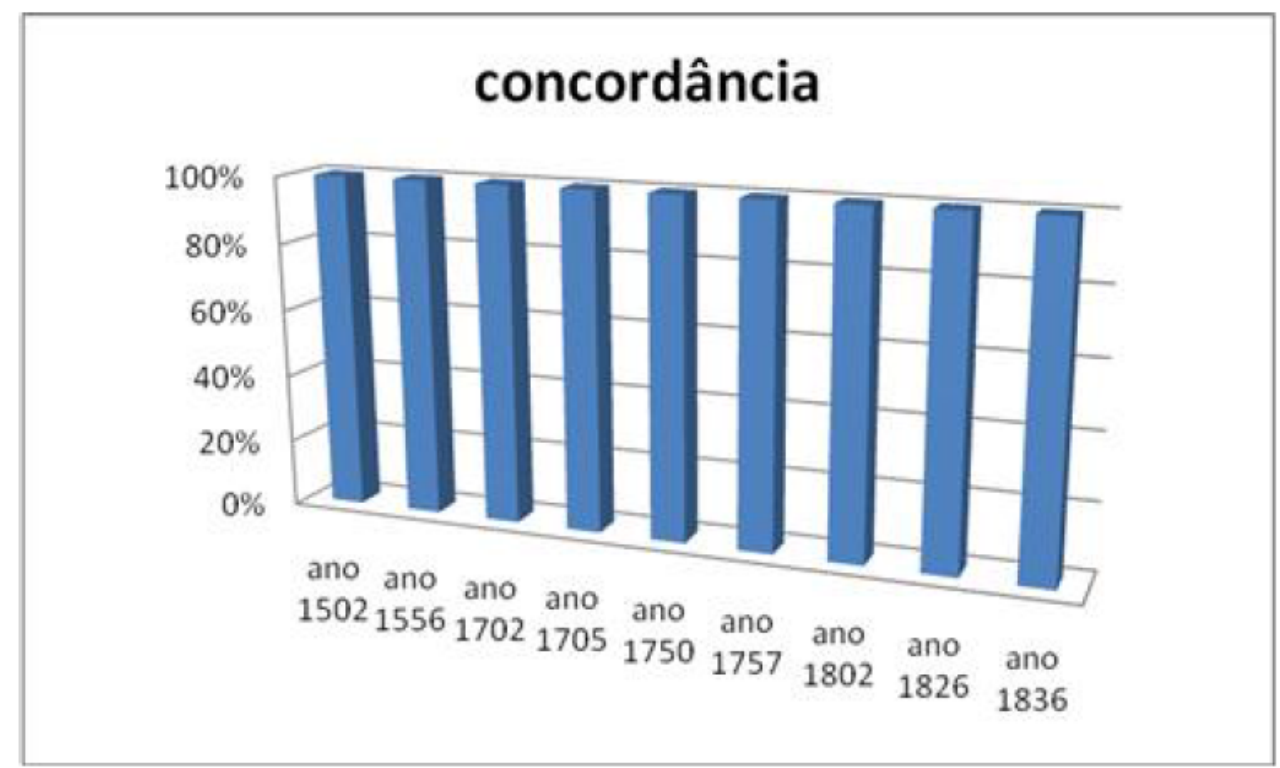

Gráfico 2. Concordância de clivadas invertidas ao longo do tempo

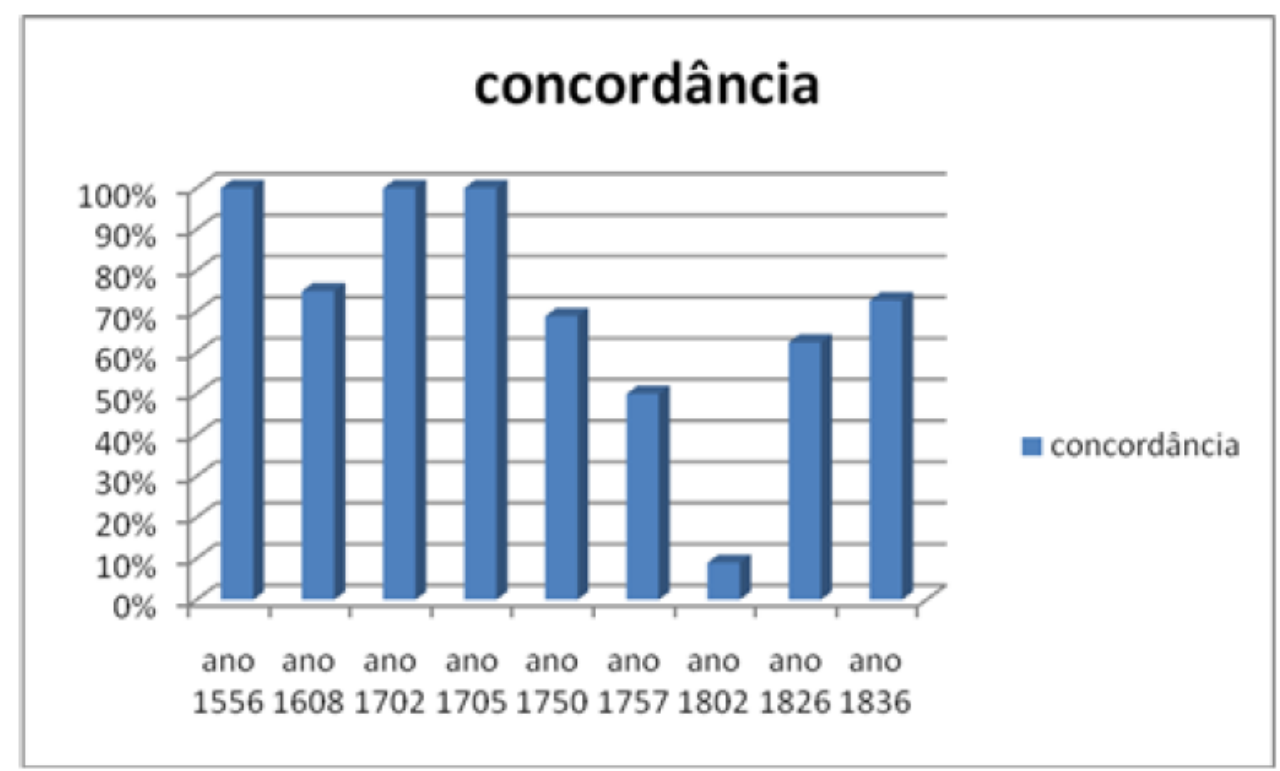

É claramente visível a diferença de relação de concordância entre canônicas e invertidas. A partir do texto do autor nascido em 1750 o número de evidências sem concordância se eleva, mas co-ocorrem com as invertidas com cópula e verbo da sentença encaixada no presente, que seriam ambíguas, como mencionado anteriormente. Haveria, portanto, possibilidades diferentes: se considerarmos que as sentenças ambíguas, na ver- 
dade, não apresentam concordância, mas cópula invariável, então o aparecimento de casos sem concordância é significativo, nos textos do corpus, a partir das primeiras evidencias desde o desaparecimento dos casos de concordância de passado (cópula no passado).

Por outro lado, se acreditarmos que muitos dos casos não se tratam de invariabilidade da cópula, mas de concordância temporal, então estaremos lidando com a coocorrência de sentenças cuja cópula foi gramaticalizada (observadas na ausência da concordância) e casos de concordância. Talvez isso nos auxilie como indício de que a possibilidade da cópula ter se gramaticalizado não acarrete a substituição total e imediata das formas com concordância, ou seja, não gramaticalizadas, o que poderia explicar a concordância de passado no texto do século XIX, a única encontrada em um espaço de tempo de quase 3 séculos no corpus, considerando o ano de nascimento do autor. Ou seja, as duas formas podem coocorrer por um espaço de tempo bastante razoável. Isso explicaria por que não é totalmente descartável, embora menos natural, a possibilidade de sentenças como (7):

\section{(7) A Maria foi que comeu o bolo.}

Embora não sendo tratada nesse trabalho, a diferença da relação de concordância entre clivadas canônicas e invertidas ocorre também no português atual, no âmbito da concordância de pessoa, como aponta Kato (2009):

(8) a. Sou eu que sou preguiçosa.

b. São as crianças que fazem barulho.

c. Eu é que sou preguiçosa $/{ }^{*} \mathrm{EU}$ sou que sou preguiçosa.

d. Nós é que fazemos o trabalho./ ${ }^{*}$ NÓS somos que fazemos o trabalho.

Nas canônicas ainda restam resquícios de elemento lexical pela presença da concordância. Portanto, se a cópula está gramaticalizada, como afirma Kato, é nas invertidas que ela está mais distante do estatuto de verbo e, portanto, de item lexical. 
Ainda em Kato, vemos a possibilidade de apagamento da cópula. A autora aborda, entretanto, esse apagamento em contexto de cópula em posição inicial da sentença:

(9) a. Foi [FO PEDRO] que a Maria viu.

b. É [FO PEDRO] que a Maria viu.

c. [FO PEDRO] que a Maria viu.

Não entrando em discussões muito aprofundadas a respeito da origem do apagamento da cópula em clivadas, mas considerando a relevância de um estudo futuro, sugiro pensarmos se não é o caso de investigar se esse apagamento não decorre a partir das clivadas invertidas.

Pensando em termos empíricos e também nos dados diacrônicos deste estudo, é possível sugerir que, com a invariabilidade da cópula, que parece ocorrer mais tipicamente nas clivadas invertidas, considerando que ela é menos natural em canônicas, houve a reanálise de é que como expressão focalizadora, resultando posteriormente no apagamento que pode se dar na forma fonológica, visto que, embora a cópula seja um monossílabo tônico, ela perde a saliência prosódica para o foco, que a precede imediatamente, e aparece menos saliente que o próprio complementizador. Esta é uma questão que pode ser investigada na posteridade.

\section{Considerações Finais}

Neste estudo, foram analisadas sentenças clivadas invertidas em textos do corpus histórico do português, Tycho Brahe. Ciente da necessidade de mais dados para poder chegar a conclusões mais sólidas, foi feita a descrição dos dados e o levantamento de possíveis discussões futuras em torno da gramaticalização da cópula e do apagamento da mesma.

Foi visto que sentenças que apresentam concordância de presente poderiam ser consideradas ambíguas, pois podem se tratar de concordância propriamente dita, ou de cópula invariável, sendo a concordância mera coincidência. Essa ambiguidade pode difi- 
cultar a descrição do fenômeno, visto que, não podemos saber em que momento as sentenças com concordância de presente passam a ser analisadas com cópula invariável focalizadora nos textos do corpus.

Mesmo diante de poucos dados, este estudo concorda com a análise de Kato (2009) e assume a gramaticalização da cópula, bem como assume perda de valor semântico, perda de autonomia, caráter acessório e apagamento opcional da mesma. $\mathrm{O}$ fenômeno da gramaticalização seria condicionado pela reanálise da cópula como elemento focalizador, totalmente dependente dos outros elementos da sentença, e não mais como verbo com conteúdo semântico e expressividade mais independentes.

\section{Bibliografia}

GALVES, C.; FARIA, P. Tycho Brahe Parsed Corpus of Historical Portuguese. 2010. Disponível em: http://www.tycho.iel.unicamp.br/ tycho/corpus/en/index.html.

GELDEREN, E. van. Grammaticalization as Economy. Amsterdam: John Benjamins, 2004.

HOPPER, P. J.; TRAUGOTT, E. C. Gramaticalization. Cambridge: University Press, 1993.

KATO, M. A.; RIBEIRO, I. A evolução das estruturas clivadas no português: período V2. In: LOBO, T.; RIBEIRO, I.; CARNEIRO, Z.; ALMEIDA, N. (Org.). Para a história do português brasileiro. Salvador: EDUFBA, 2006. p. 165-182.

KATO, M. A. Mudança de ordem e gramaticalização na evolução das estruturas de foco no Português Brasileiro. Estudos Linguísticos, São Paulo, v. 38, n. 1, 2009, p. 375-385.

LIGHTFOOT, D. How New Languages Emerge. Cambridge: University Press, 2006.

MEILLET, A. L'évolution des formes grammaticales. Paris: F. Alcan, 1912.

SILVEIRA, D. M. Clivadas e pseudo-clivadas na história do português: uma análise diacrônica das estruturas de foco e implicações da gramática V2. Dissertação (Mestrado em Linguística) - Universidade Estadual de Campinas, 2014.

Data de submissão na OJS: 02/04/2016 Data de aceite registrado na OJS: 27/09/2016 